\title{
Psychogenic Vaginismus
}

National Cancer Institute

\section{Source}

National Cancer Institute. Psychogenic Vaginismus. NCI Thesaurus. Code C35113.

Involuntary spasm of the outer muscles of the vagina during penetration that results from a psychological cause. 